\title{
A Rare Cause of Stomach Gangrene: Necrotizing Gastritis
}

\author{
Hicham El Bouhaddouti, Tarik Souiki, Khalid Mazine, Abdelmalek Ousadden, \\ Khalid Mazaz, Khalid Ait Taleb \\ Department of Visceral Surgery, University Hospital Hassan II-Fes, Faculty of Medicine and Pharmacy of Fez, \\ Sidi Mohamed Ben Abdellah University, Fez, Morocco \\ Email: h.elbouhaddouti@yahoo.fr
}

Received 23 December 2014; accepted 10 February 2015; published 16 February 2015

Copyright (C) 2015 by authors and Scientific Research Publishing Inc.

This work is licensed under the Creative Commons Attribution International License (CC BY). http://creativecommons.org/licenses/by/4.0/

c) (i) Open Access

\begin{abstract}
Necrosis of the stomach is rare. It occurs when there is vascular anomalies, gastric volvulus or herniation and in infectious gastritis. We report a case in which infectious gastritis leads to a necrotizing gastritis that is treated with urgent gastrectomy.
\end{abstract}

\section{Keywords}

\section{Gastric Necrosis, Necrotizing Gastritis, Surgery}

\section{Introduction}

The stomach is very resistant to ischemia due to its rich blood supply. Necrosis of the stomach is a rare, often fatal disease which may be due to vascular, chemical, mechanical or infectious etiologies. Infection is the rarest cause of gastric ischemia but a life threatening form is acute phlegmonous gastritis [1], which can be best described as a condition of diffuse cellulitis confined to the stomach. The acute necrotizing gastritis is a cause of gastric necrosis. It appears to be a variant of phlegmonous gastritis [2]. We report a case of a young girl who has suffered from gastric necrosis without any vascular, chemical or mechanical cause.

\section{Case Report}

An 18-year-old young lady was admitted to the general surgery emergency with a 24-hour duration of pain in the epigastrium. The pain was severe, continuous, associated with nausea. There was no history of haematemesis or vomiting but she suffered of intermittent epigastric pain. On examination, the vital signs were: Temperature $38.5^{\circ} \mathrm{C}$, Pulse 115/min, Respiratory rate 26/min, Blood pressure 90/60 $\mathrm{mmHg}$. Abdominal examination found

How to cite this paper: Bouhaddouti, H.E., Souiki, T., Mazine, K., Ousadden, A., Mazaz, K. and Taleb, K.A. (2015) A Rare Cause of Stomach Gangrene: Necrotizing Gastritis. Open Journal of Gastroenterology, 5, 7-10.

http://dx.doi.org/10.4236/ojgas.2015.52002 
diffuse tenderness with rigidity on palpation. Routine hemogram showed leucocytosis at 16,000 e/dl, serum urea and creatinine levels were within normal limits. After initial resuscitation with intravenous fluids and antibiotics, decision was taken to proceed for an emergency laparotomy. On exploration, the peritoneal cavity was filled with infected haemorrhagic fluid. There was gangrene of the proximal 1/3rd of the stomach (Figures 1-3) with intact extrinsic blood supply. There was normal pulsation of the gastric vessels. The esophagus, small intestine, colon and rectum were pink and viable. Total gastrectomy with Roux-en-Y esojejunostomy was done. This was followed by a feeding jejunostomy. In the postoperative days she had a pneumopathy well controlled with antibiotics. She was discharged on the 8th postoperative day.

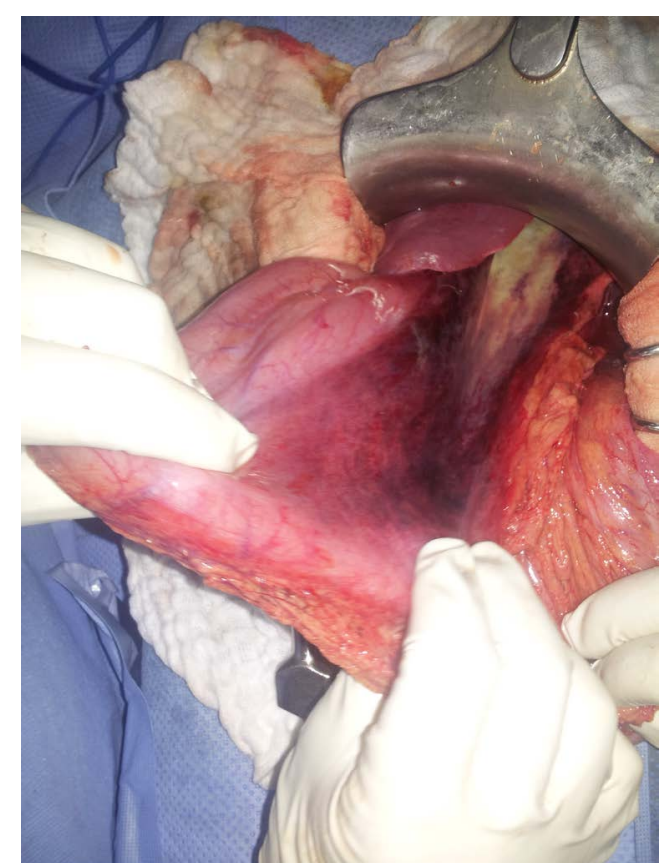

Figure 1. Intraoperative front view of the necrosed stomach.

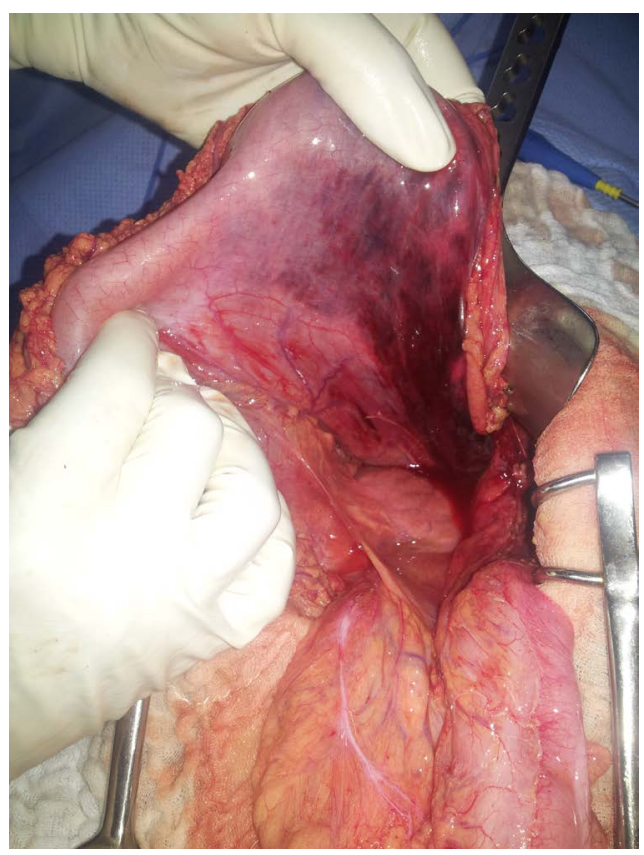

Figure 2. Intraoperative rear view of the necrosed stomach. 


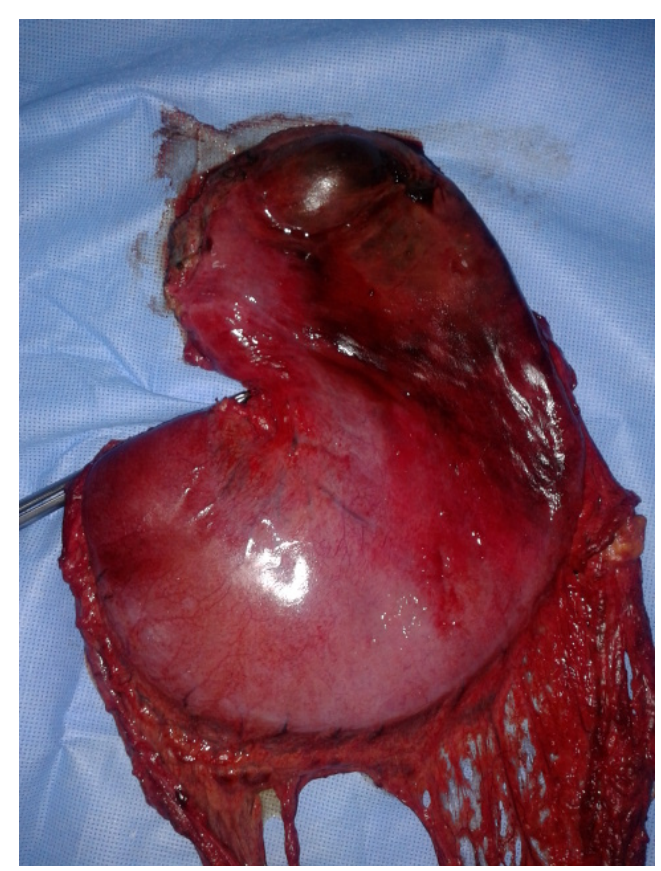

Figure 3. Specimen of the resected stomach.

\section{Discussion}

Gastric necrosis is a rare and fatal condition. Etiology includes thromboembolism and occlusion of major arterial supply, ingestion of corrosive agents, volvulus of the stomach, herniation of the stomach through the diaphragm, bulimia nervosa, iatrogenic gelfoam embolism, endoscopic haemostatic injections and infectious gastritis [3] [4].

The acute necrotizing gastritis is the rarest cause of gastric gangrene. In the present case, there is no history of ingestion of caustic substances; neither volvulus nor herniation of the stomach was observed intraoperatively. Also, the stomach vessels pulses were normal. So the most probable cause of the gastric necrosis was infectious gastritis. It begins as phlegmonous (suppurative) gastritis (PG), and then it progresses to the lethal severe form: acute necrotizing gastritis.

The pathogenesis of acute necrotizing gastritis is unclear, although predisposing factors include chronic gastritis, increased age, alcoholism, hypoacidity, protein-energy malnutrition and immunosuppression [5] [6]. Organisms isolated from the gastric wall include hemolytic streptococci, proteus, E. coli and clostridium welchii [2] [3].

Patients with acute PG have severe upper abdominal pain with associated fever, nausea and vomiting. The pain usually increases in severity as the abscess enlarges, does not radiate and is non-colicky in nature. Physical findings include fever, signs of peritoneal irritation and, occasionally, a palpable mass [3] [5]. Diagnosis may be delayed due to the lack of typical signs and this, combined with the rapid progression to peritonitis, often results in a fatal outcome. The diagnosis of the gastric necrosis was made in our case before perforation of the stomach and peritonitis. Consequently, the post-operative follow-up was relatively simple.

PG can be diagnosed by upper gastrointestinal endoscopy, CT scan, or endoscopic ultrasound [8]. Itsendoscopic findings can show purple colored gastric mucosa covered with dirty necrotic materials. However, esophagus and duodenum are rarely involved. On CTscan, markedly thickened gastric wall can be seen in PG, and collection of air is seen in emphysematous cases [7] [8]. Absolute diagnosis is made, most frequently, at laparotomy [8].

If a diagnosis of ischaemia is being considered, resuscitation and intravenous antibiotics should be initiated immediately, followed by an emergency exploratory laparotomy. Resection of a necrotic stomach is required, with total gastrectomy if necessary, like we did in our case. During the last 50 years, there have been reports of the successful treatment of patients with phlegmonous gastritis by medical therapy alone [9]. But before considering medical treatment, there must be no doubt gastric ischemia. 
Diagnosis and treatment must be expeditious, because mortality rates for gastrectomy due to acute ischaemia can reach $50 \%[10]$.

\section{Conclusion}

Gastric necrosis is a rare condition. This can lead to mistake the right diagnosis and late treatment. Endoscopy and CT scan can help diagnosis, but in the most frequent cases it's made at laparotomy. The resection of the necrotic stomach is the main treatment.

\section{References}

[1] Stein, L.B., Greenberg, R.E., Ilardi, C.F., et al. (1989) Acute Necrotizing Gastritis in a Patient with Peptic Ulcer Disease. The American Journal of Gastroenterology, 84, 1552-1554.

[2] Strauss, R.J., Friedman, M., Platt, N., Gassner, W. and Wise, L. (1978) Gangarene of the Stomach: A Case of Acute Necrotizing Gastritis. The American Journal of Surgery, 135, 253-257. http://dx.doi.org/10.1016/0002-9610(78)90111-3

[3] Richieri, J.P., Pol, B. and Payan, M.J. (1998) Acute Necrotizing Ischemic Gastritis: Clinical, Endoscopic and Histopathologic Aspects. Gastrointestinal Endoscopy, 48, 210-212. http://dx.doi.org/10.1016/S0016-5107(98)70168-3

[4] Dharap, S.B., Ghag, G. and Biswas, A. (2003) Acute Necrotizing Gastritis. Indian Journal of Gastroenterology, 22, 150-151.

[5] Haubrich, W.S., Schaffner, F. and Berk, J.E., Eds. (1995) Bockus Gastroenterology. 5th Edition, W. B. Saunders Co., Philadelphia.

[6] Takeuchi, M., Uno, H., Matsuoka, H., et al. (1995) Acute Necrotizing Gastritis Associated with Adult Tcellleukemia in the Course of Chemotherapy. Gan To Kagaku Ryoho, 22, 289-292.

[7] Mukhopadhyay, M., Saha, A.K., Sarkar, A., Tripathi, S.N., Biswas, S., Mandal, D. and Mukherjee, S. (2011) Gastric Gangrene Due to necrotizing Gastritis. Indian Journal of Surgery, 73, 65-67.

http://dx.doi.org/10.1007/s12262-010-0134-0

[8] Soon, M.S., Yen, H.H., Soon, A. and Lin, O.S. (2005) Endoscopic Ultrasonographic Appearance of Gastric Emphysema. World Journal of Gastroenterology, 11, 1719-1721. http://dx.doi.org/10.3748/wjg.v11.i11.1719

[9] Hu, D.C., McGrath, K.M., Jowell, P.S. and Killenberg, P.G. (2000) Phlegmonous Gastritis: Successful Treatment with Antibiotics and Resolution Documented by EUS. Gastrointestinal Endoscopy, 52, 793-795. http://dx.doi.org/10.1067/mge.2000.108926

[10] Kim, G.Y., Ward, J., Henessey, B., et al. (2005) Phlegmonous Gastritis: Case Report and Review. Gastrointestinal Endoscopy, 61, 168-174. 
Scientific Research Publishing (SCIRP) is one of the largest Open Access journal publishers. It is currently publishing more than 200 open access, online, peer-reviewed journals covering a wide range of academic disciplines. SCIRP serves the worldwide academic communities and contributes to the progress and application of science with its publication.

Other selected journals from SCIRP are listed as below. Submit your manuscript to us via either submit@scirp.org or Online Submission Portal.
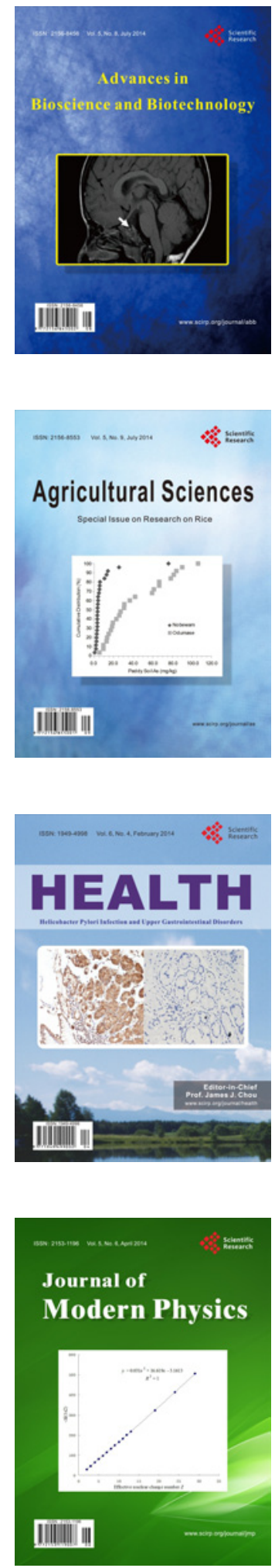
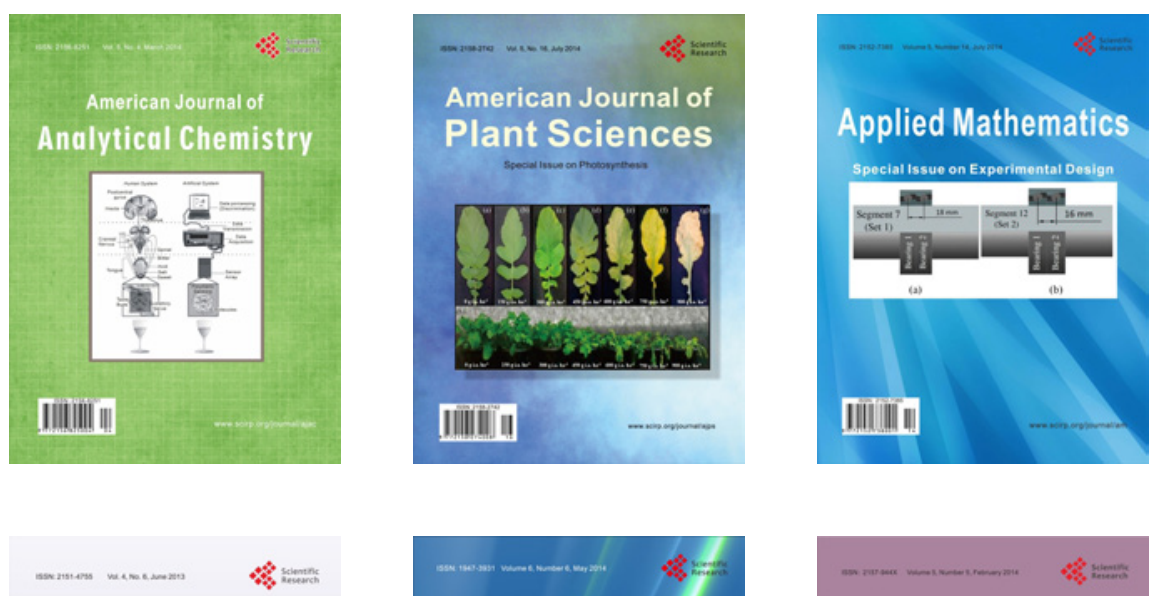

Creative Education
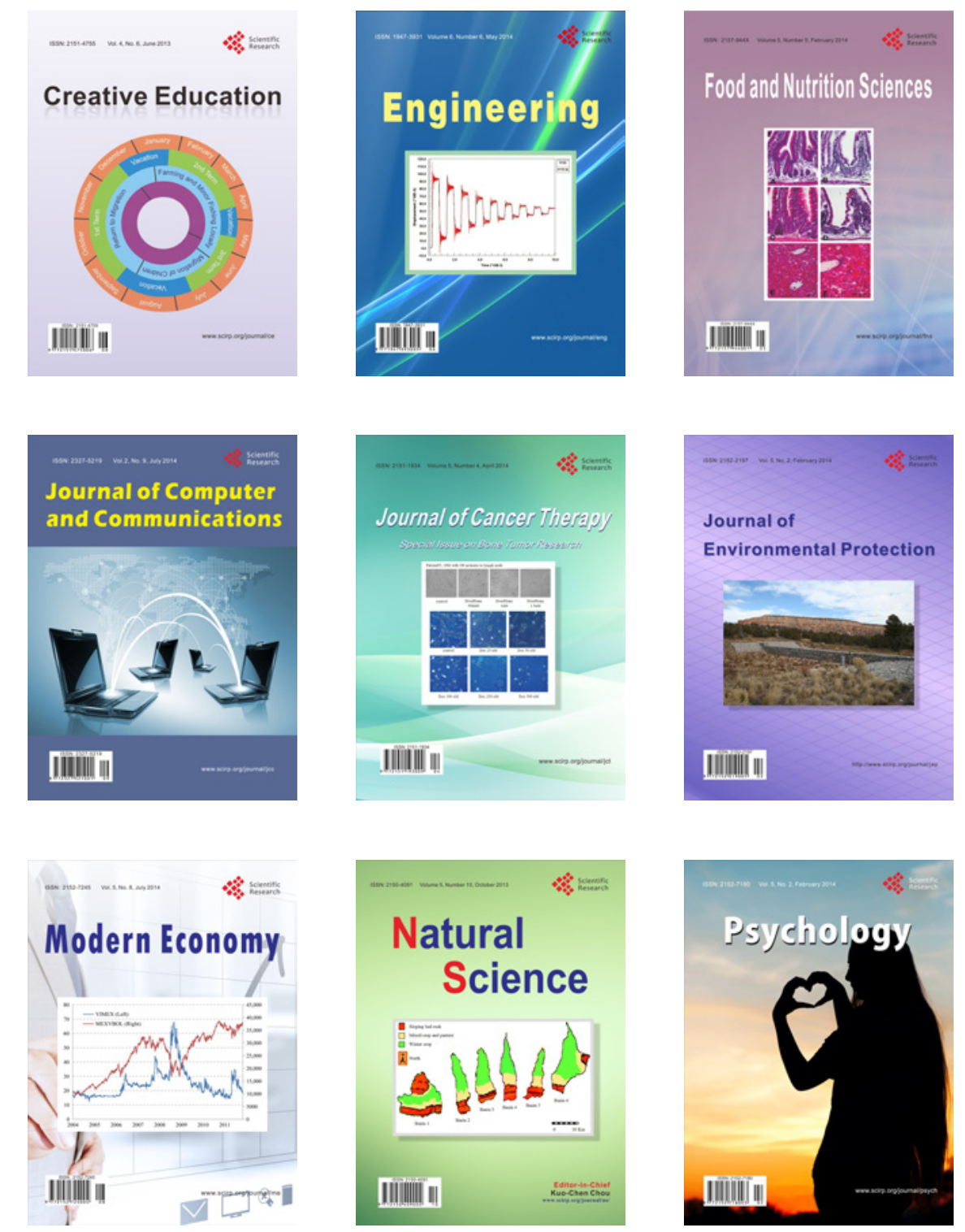